\title{
CONCURSO DE VIVIENDAS ECONÓMICAS PARA EMPLEADOS: UN PROYECTO MODERNO EN COLOMBIA
}

Arquitecto Samuel Jaimes Botia*
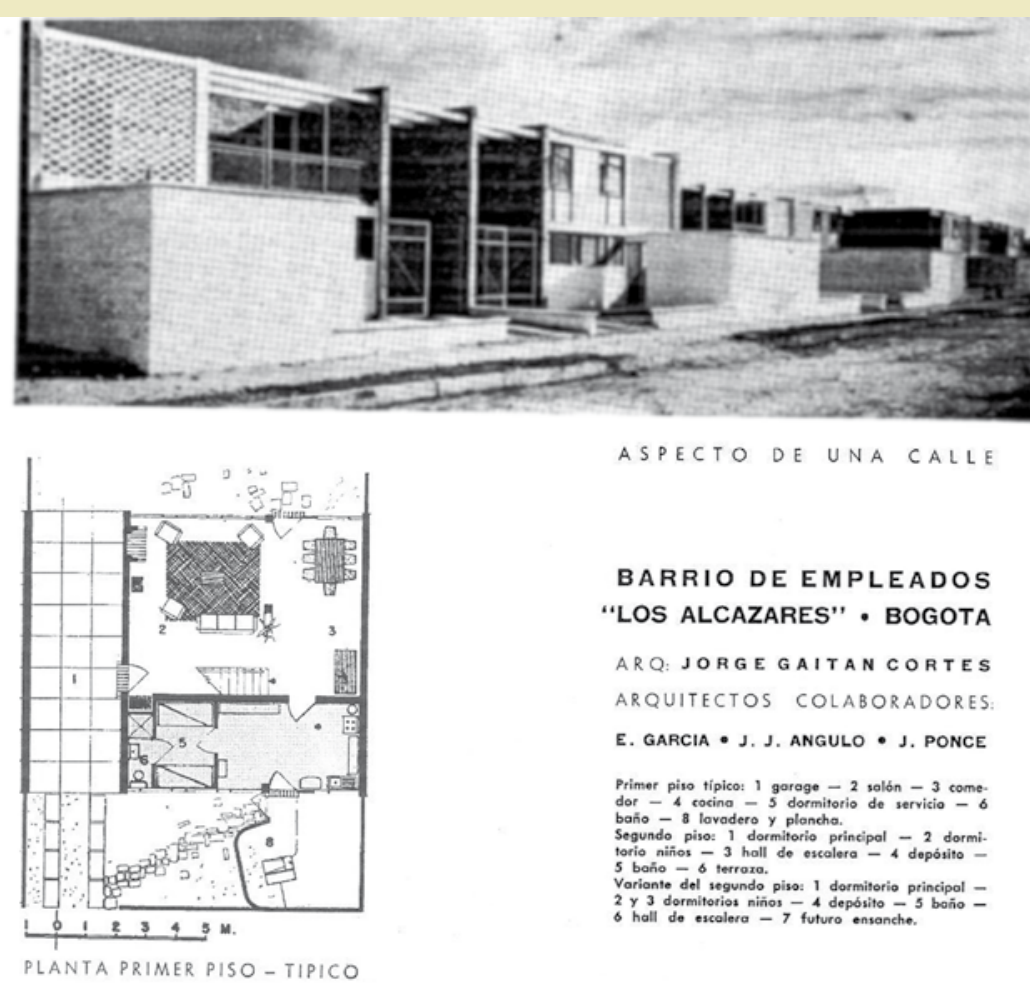

ASPECTO DE UNA CALLE

BARRIO DE EMPLEADOS

"LOS ALCAZARES" - BOGOTA

ARQ: JORGE GAITAN CORTES

ARQUITECTOS COLABORADORES:

E. GARCIA - J. J. ANGULO - J. PONCE

Primer piro típico: 1 gorage -2 solón -3 come.
dor -4 cocinas -5 dormitorio de servicio -6

Segundo piso: 1 dormitorio principal -2 dormi

5 bońo - 6 terroxo.

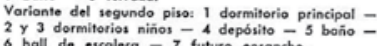
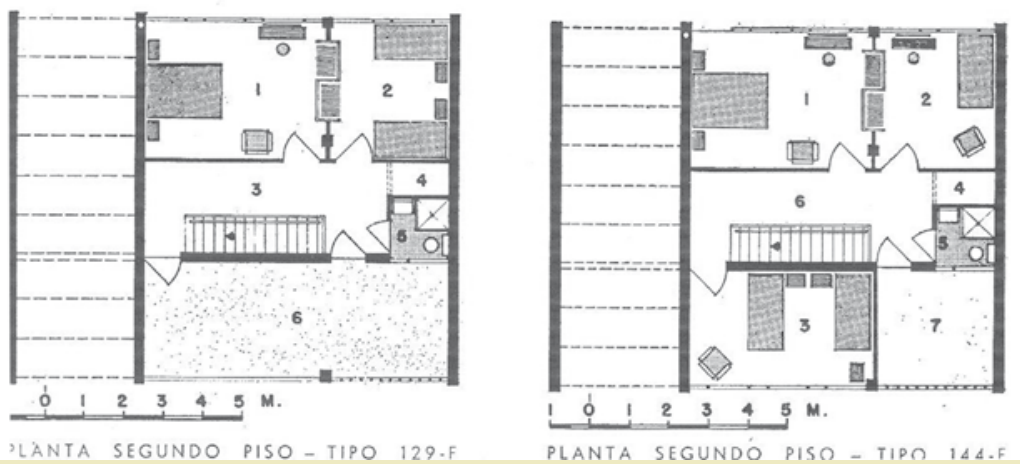

\section{RESUMEN}

Este texto es el informe de investigación sobre el análisis del concurso de vivienda económica para empleados promovido por el Instituto de Crédito Territorial en Colombia. El análisis reflexiona no sólo sobre los proyectos presentados al concurso, sino de sus autores junto a su obra posterior referida al habitat del obrero colombiano, que a manera de repliegue indaga sobre la modernidad en Colombia.

\section{PALABRAS CLAVE}

Arquitectura moderna, Vivienda económica, Modernidad, Concurso de vivienda. 

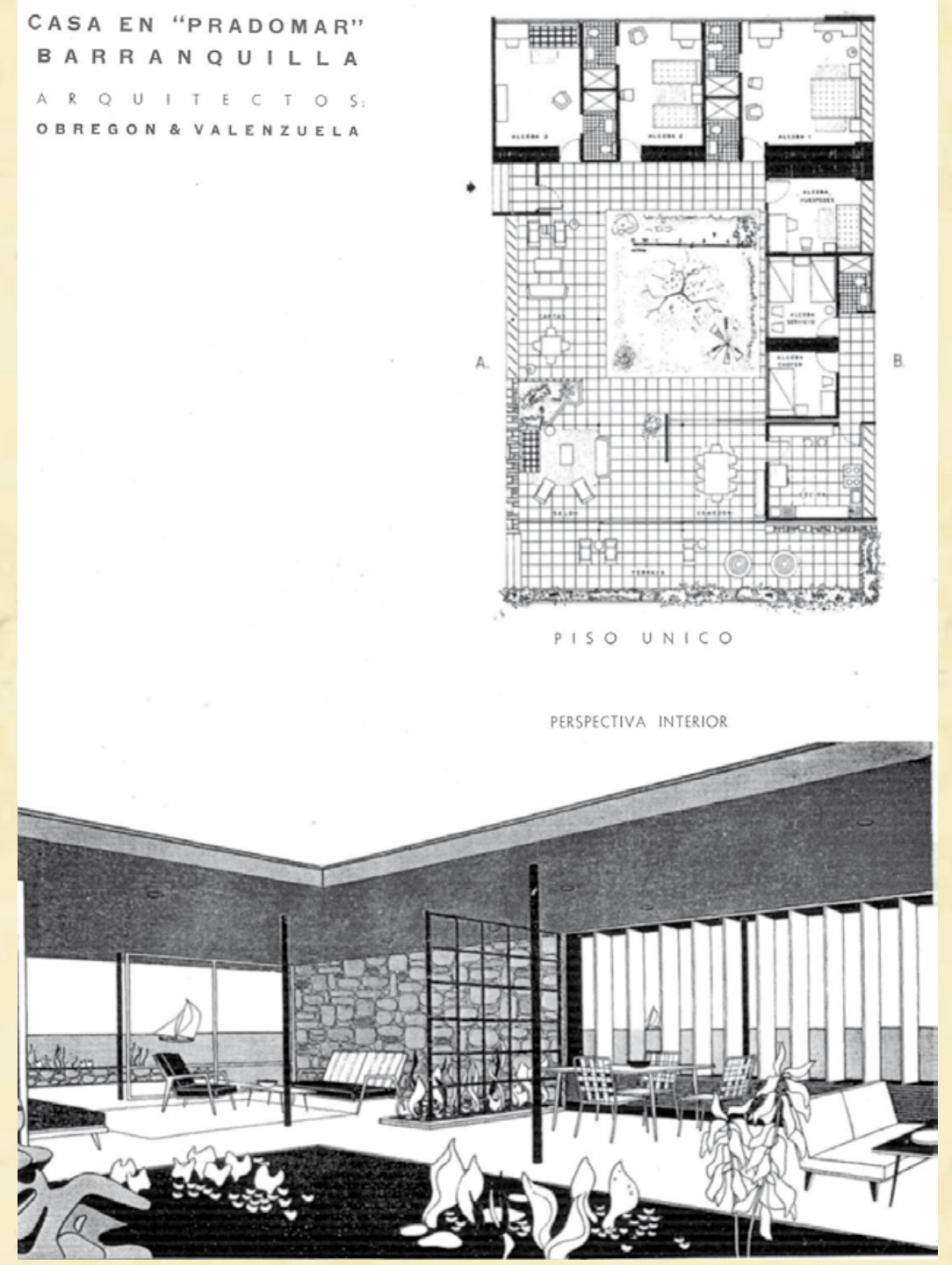

\section{ABSTRACT}

This text is the investigation report on the analysis of the Contest of Economic Houses for Employees, promoted by the Instituto de Crédito Territorial in Colombia. The analysis reflects not only on the projects presented to the contest, but about its authors together with their later work regarding the habitat of the Colombian worker, whom also investigates on modernity in Colombia.

\section{KEYWORDS}

Modern architecture, economic housing, modernity, housing contest. 
I Me refiero a la palabra Interés en relación al Conocimiento de la manera como es utilizada por HABERMAS; en el que se abre el acceso a los hechos históricos, mediante un conocimiento semiológico ligado a la interpretación y la comprensión de sentido, en lugar de la simple observación y narración de los hechos. HABERMAS, Jürgen, Conocimiento e Interés. Taurus Ed. Madrid, 1982.

2 HABERMAS plantea el Proyecto Moderno como un proyecto inacabado, no superado, un proyecto con ideales sociales pendientes y diferentes en cada contexto; es desde esta perspectiva como se aborda la pregunta: ¿Cómo debe vivir el obrero colombiano? Y, que por primera vez se preguntan los gremios, e gobierno, y la academia, por la función social de la arquitectura; es así como sugiero sea analizado el Concurso. HABERMAS, Jürgen, El Discurso Filosófico de la Modernidad. Taurus Ed. Madrid, 1989.

3 Plinio Mendoza Neira, Director de la Exposición. El Tiempo, Bogotá abril 10 de 1938. En la exposición del IV centenario de Bogotá: el mapa de la modernidad. RODRÍGUEZ, Gabriel Felipe. Revista Textos, Editorial UNAL. Bogotá, 2005.

4 "Esta exposición contendrá tres aspectos principales del desarrollo que a lo largo de la historia han tenido las clases humildes o del pueblo. En primer término vendrá el "cercado chibcha" donde se exhibirán todos los usos y costumbres de la época; luego las condiciones actuales del obrerismo urbano y a continuación la forma como se ha proyectado liberar para la vida social y mejorar las condiciones físicas de todo el vasto conglomerado obrero local. Esta exposición, como podrá observarse, es de suma importancia para la educación popular y para el progreso obrero. El Tiempo, Bogotá, mayo 26 de 1938. En Op. Cit., p. 53.

\section{INTRODUCCIÓN}

Al plantearse las preguntas: ¿Cuál ha sido el impacto del Concurso de Viviendas Económicas para Empleados en Colombia? ¿Cómo poder analizarlo? ¿Desde qué referentes? Empezó a ser cada vez más interesante a medida que se indagaba sobre ello, no sólo mediante la búsqueda historiográfica, (el cual da muy poca o ninguna importancia al tema y con imprecisiones) sino, al revisar a cada uno de los actores que intervinieron en el concurso, ya fuese de una manera directa o indirecta. Ahora bien, evidenciar a los actores introduce un método de análisis, que empieza a ser crítico en el momento en que se cruza con un contexto histórico (social, político y económico) y geográfico; este cruce permite visualizar su pensamiento proyectivo y los Intereses' particulares que se entretejen; sin embargo, hablar del pensamiento que se desarrolla alrededor de cada una de las propuestas y cómo a partir de sus obras posteriores, las explicamos a manera de repliegue, es como particularmente y de manera paralela deseo escribir sobre la evolución de un Proyecto Moderno² $^{2}$ para Colombia.

A partir de los años treinta se suceden en Colombia los gobiernos liberales con ideas modernizantes que intentan poner al día los medios de comunicación, las condiciones de salud y la industria en su proceso de sustitución de importaciones, fueron estos, algunos de los hechos, por los cuales, se inicia el desbordamiento físico de las ciudades; el ejemplo que mejor ilustra este momento, es sin duda, la exposición nacional del IV centenario de Bogotá, realizada en 1938, en el Barrio Palermo, uno de los barrios de la periferia bogotana; la exposición buscaba "una moderna orientación, de modo que reflejase de manera ordenada y sistemática la realidad industrial y agrícola del país" ${ }^{3}$, del mismo modo, ponía sobre el tapete el problema de la vivienda como la necesidad más sentida por todos los sectores sociales ${ }^{4}$, adicionalmente en este mismo año, se realizó el censo con el fin de saber a ciencia cierta cuántos, cómo, y en qué condiciones vivían los colombianos.

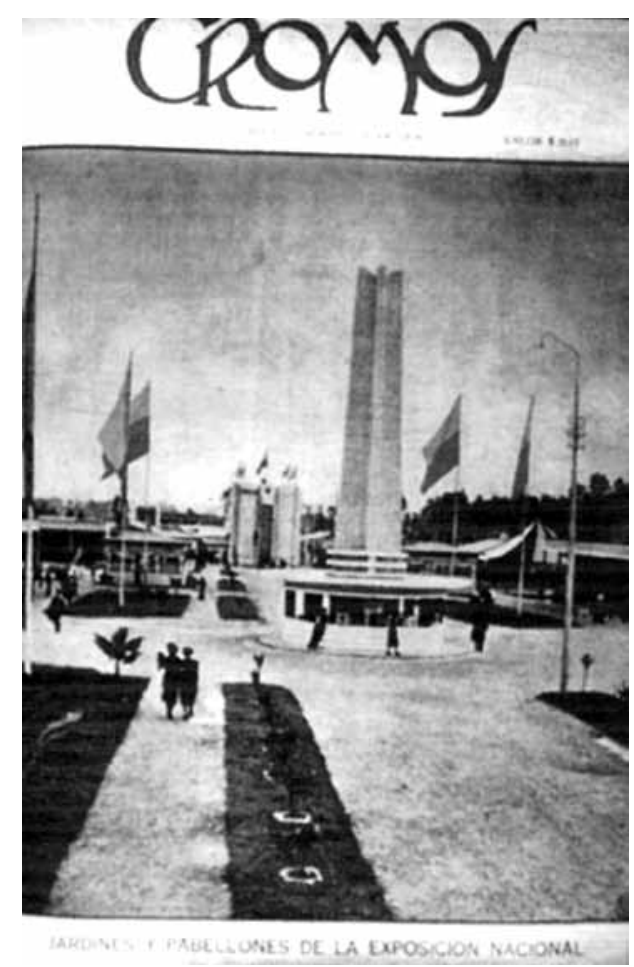




\section{EL INSTITUTO DE CRÉDITO TERRITORIAL ICT.}

El Estado consolida las presiones sociales y los esfuerzos por controlar la creciente demanda, de manera tal, que en enero de 1939, bajo el gobierno (liberal) del presidente Eduardo Santos, se crea el Instituto de Crédito Territorial ICT; un organismo autónomo especializado con patrimonio propio para dotar de vivienda al pueblo colombiano. Su acción inicial se canaliza hacia la vivienda rural pero posteriormente, luego de la creación de la sección de vivienda urbana, su acción y su capital aumentan. Esto no quiere decir que con anterioridad en Colombia no se hubiesen consolidado acciones como barrios modelos o barrios obreros, desarrollados por otras entidades gubernamentales, como el Banco Central Hipotecario BCH (1909) y el Instituto de Acción Popular (1932), para suplir el déficit de la vivienda; pero, lo que sí logra el ICT, es iniciar por su propia cuenta la Proyectación, la Experimentación Técnica, y la Construcción directa de la Vivienda Urbana, al desarrollar barrios populares en diferentes ciudades del país.

EI ICT, creado mediante Decreto Ley 200, inicia actuando con destinación principal hacia la Vivienda Rural y a poblaciones cercanas a las grandes ciudades, con el fin de frenar la migración del campo a la ciudad, acompañada de otras acciones conjuntas como fueron las escuelas rurales desarrolladas por el Ministerio de Obras Públicas MOP. En 1942 la ley 380 faculta al Ministerio de Hacienda para que le sean otorgados préstamos a los municipios y se crea la sección dentro del ICT, para desarrollar Vivienda Urbana Popular, para tal fin, se aumenta su capital en un $100 \%$. Luego de la caída del partido Liberal en las elecciones de 1946 y con intención de disminuir la presión ejercida por los sindicatos, el presidente conservador Mariano Ospina Pérez, sanciona varias medidas, entre ellas: la ley 85 donde se provee la financiación de la vivienda para los trabajadores, el aumento una vez más del $100 \%$ del capital del ICT y, finalmente, se aplicó mediante la ley 29 el impuesto del $0.5 \%$ de la renta líquida gravable para su financiación.

A finales de los cuarenta el gerente de la industria Icollantas ${ }^{5}$, Ingeniero Hernando Posada Cuellar es nombrado gerente del ICT, con el firme propósito de proyectar y construir viviendas para empleados en serie de manera taylorista; $y$ a mediados de los años cincuenta el ICT, fue autorizado por el Ministerio de Hacienda para emitir bonos de Vivienda y Ahorro con destino a la financiación de nuevas Viviendas.

\section{EL CONCURSO DE VIVIENDAS PARA EMPLEADOS Y LA CONFORMACIÓN DEL JURADO}

En 1947 el ingeniero Posada como gerente del ICT, promueve un Concurso de Vivienda Económica donde las bases discriminaban dos tipos de casas: una de tres dormitorios (A) y otra de cuatro (B); se exigía una arquitectura para un clima templado (bogotano) y construcción apareada en parcelas de I I,50 metros de frente; se sugería una construcción de viviendas en serie en un terreno ya parcelado, la posibilidad de que la vivienda gozara de un jardín o patio interior para cultivo, además de las ventajas urbanísticas en cuanto a zonas comunes se refiere para un vasto conjunto.

Participaron 26 concursantes, bajo las bases y un programa muy bien estudiado publicado por la Revista PROA; El jurado calificador del Concurso estaba configurado por los siguientes arquitectos: Jorge Arango, graduado en Chile (1946) Fundador de Muebles ARTECTO (1945), y cofundador de la Revista PROA (1947), posteriormente, Director del Departamento de Arquitectura del Ministerio de Obras Públicas MOP (1948), desde donde invita
5 La historia de Icollantas se remonta al año de 1942 en el cual se fundó la Empresa por iniciativa de empresarios colombianos en asocio con el IFI y la BF Goodrich de Estados Unidos, para superar la escasez de llantas que generó la segunda guerra mundial. 
6 En Resultados del Concurso para Vivienda Económica, Revista PROA 7, Mayo de 1947. P. 18 a los entonces recién egresados como arquitectos Fernando Martínez y Hernán Vieco, a trabajar en el proyecto de la reconstrucción de Tumaco, (municipio del Valle del Cauca, destruido por un incendio) que dirigía Wiener y Sert; Álvaro Hermida Guzmán, graduado en la Universidad de Berkeley (194I), inició trabajo con el ICT, y posteriormente con la firma Wiesner \& cía. ; Carlos Dupuy, Arquitecto de la generación de los nuevos que trabaja como diseñador para el MOP (1945) donde realiza los centros cívicos de los municipios de Corozal (Sucre) y Socorro (Santander); y Robert L. King, arquitecto norteamericano posiblemente invitado, pues no se posee referencia alguna.

El jurado en su fallo examinó el aspecto económico, técnico y sobre todo el cultural, haciendo énfasis a las costumbres hogareñas arraigadas en este sector social; mediante su dictamen se pueden realizar algunas consideraciones generales de importancia, como por ejemplo: el área construida en dos pisos oscila entre los $160 \mathrm{~m}^{2}$ de la vivienda tipo $\mathrm{A}$, a los $190 \mathrm{~m}^{2}$ de la vivienda tipo $B$; todas las propuestas destacan tanto las áreas libres de patios interiores, como las áreas comunes de antejardines, las cuales pueden ser usadas para el descanso (recreo) y/o cultivo (huerto); el ingreso del vehículo en el programa de la vivienda económica y finalmente el $90 \%$ de las propuestas plantean el área de salón comedor en un solo espacio, incluida una zona de lectura o biblioteca con su respectivo control climático (chimenea).

Por otra parte, las distinciones de los premios fueron establecidos de la siguiente manera: obtuvieron el ler premio en la casa tipo A (Fig. 2), al grupo de arquitectos Rafael y Jesús María Obregón \& Pablo Valenzuela (egresados de la Universidad Católica de Washington); el segundo premio en la casa tipo A (Fig. 3), y el tercer premio en la casa tipo B (Fig. 6), respectivamente, al grupo de Gabriel Serrano (Ingeniero de la Universidad Nacional de Colombia UNAL), Gabriel Largacha (graduado de Arquitecto de la misma universidad), y Carlos Arbeláez (arquitecto de la UNAL con especialización en USA en 1943); el tercer premio en la casa tipo A (Fig. 4), fue concedido al arquitecto Fabio Robledo director de la firma Robledo Hermanos \& Cía.; luego de declarar desierto el ler premio de la casa tipo B, el segundo premio (Fig. 5), fue para el grupo conformado por los recién egresados arquitectos Fernando Martínez (UNAL 1947) y Hernán Vieco (UNAL 1948); y por último el grupo conformado por los arquitectos Jorge Gaitán (UNAL - YALE, USA 1942), Gabriel Solano (UNAL 194I), y Álvaro Ortega (Mc.Gill, Cad. \& Harvard, USA 1944), fueron los que obtuvieron una Mención Honorífica en la casa tipo A (Fig. 7), y que la Revista PROA, publicó: "Este proyecto a juicio de varios profesionales fue el más inteligentemente estudiado, pero no se sometió rigurosamente a las bases del concurso. El Jurado recomendó su utilización como modelo de experimentación en los terrenos y laboratorios que el Instituto de Crédito Territorial dispondrá próximamente para tal fin”6.

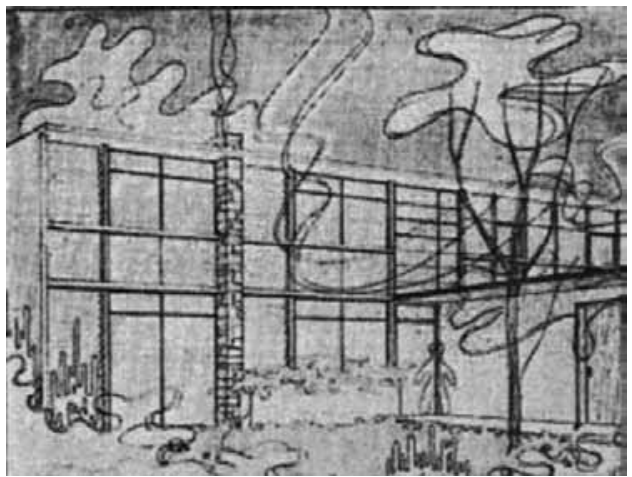

Figura 2. 1er. puesto Vivienda Tipo A Arqts. Obregón y Valenzuela.

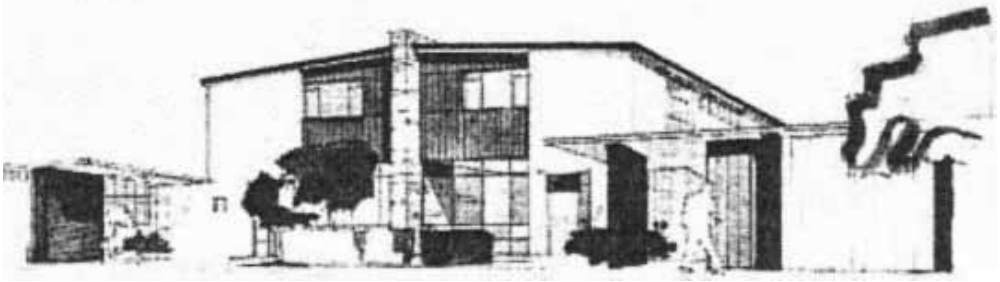

Figura 3. 2do. puesto Vivienda Tipo A-Arqts. Serrano, Largacha, Arbeláez. 


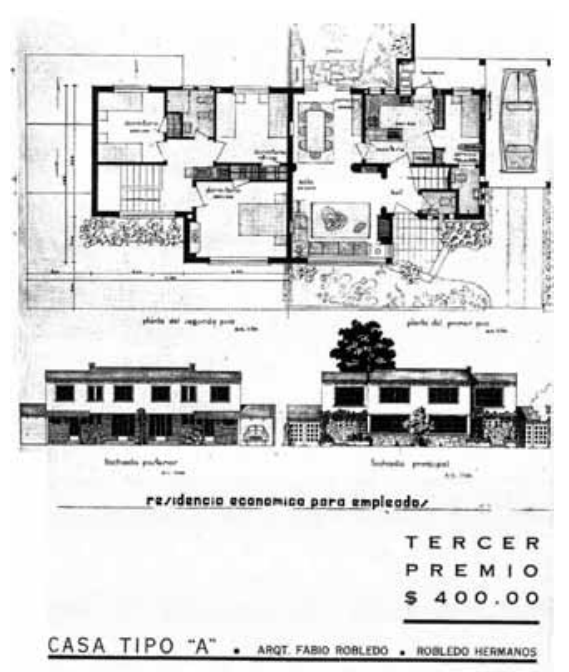

PROICE

Figura 4. Casa Tipo A

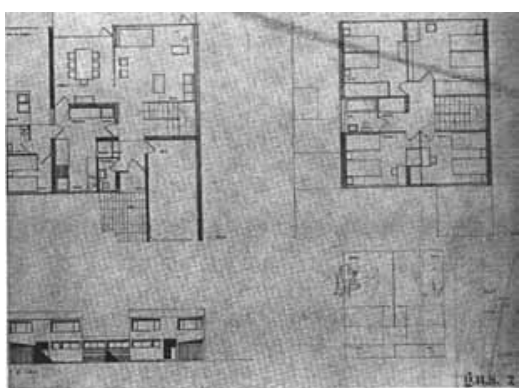

$S E G \cup N D O$

$P R E M I O$

$\$ 800.00-$
CASA TIPO B

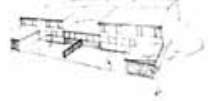

$\mid \|$

PROAE

Figura 5. Casa Tipo B

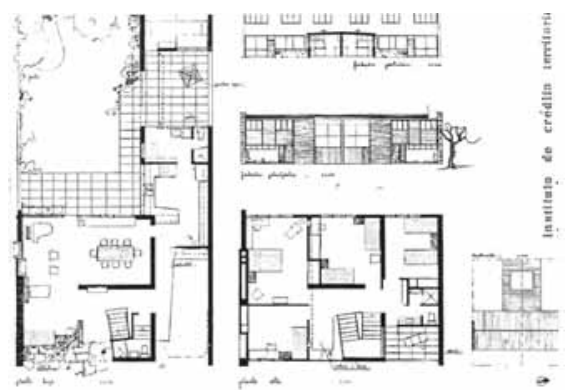

TERCER

PREMIO

$\$ 400.00$

C A S A

TIPO "B"

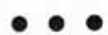

INDICE

Figura 6. 3er. puesto Vivienda Tipo B. Arq. Serrano

\section{LA REVISTA PROA Y LA DIFUSIÓN DE LA MODERNIDAD}

Una de las condiciones por las cuales adquiere importancia la revista PROA, radica en que la "Historiografía en Colombia"7 la ha situado como uno de los medios por los que la arquitectura moderna se difunde; realizada ésta, mediante la iniciativa de un grupo de arquitectos que debatía y cuestionaba los temas arquitectónicos y urbanos de actualidad en el país, contextualizándolo con los principios de un furibundo Le Corbusianismo predicado por Carlos Jiménez ${ }^{8}$. Estos temas inician en la Revista con "La crisis de las habitaciones en Colombia"”, un pequeño artículo escrito por J. B. Garcés Navas, en el cual, desde una perspectiva positivista realiza un análisis de la vivienda rural y urbana; a partir de las estadísticas proporcionadas por el censo de 1938, establece las causas apoyado en el discurso higienista para la vivienda rural, y desde la migración y la industrialización para la vivienda urbana, culminando con propuestas de acción por parte del Estado y de los particulares de manera conjunta y coordinada. De igual manera y, desde la misma perspectiva, el Editorial escrito por Carlos Jiménez plantea el problema del "crecimiento desordenado y vertiginoso de las ciudades", para lo cual considera que la publicación de la Revista será el aporte y el medio por el cual estudiar y conocer ampliamente de los problemas de la arquitectura y el urbanismo, a nivel nacional e internacional; de esta manera la Revista se lanza a un público amplio y mixto, (teniendo presente lo árido del contexto) cubría desde los profesionales especialistas en el área, los gobernantes y las entidades oficiales, hasta los ciudadanos particulares interesados en el tema urbano.

En las siguientes publicaciones ${ }^{10}$ se encuentran diversos artículos que tratan temas sociales, en el que se aborda el tema de la vivienda económica para obreros y que cuestionan la función social de la arquitectura; ante estos se coloca en paralelo esquemas o propuestas de transformación posible de la ciudad, entre los cuales están: "Para que Bogotá sea una ciudad moderna", "La carrera 10", "Las futuras grandes avenidas de Bogotá", y "Bogotá puede ser una ciudad moderna"; son todos ellos ejercicios que a manera de laboratorio urbano (académicos en algunos casos), que se conjugan con los realizados en otras ciudades a nivel internacional como "la ciudad del periodista en Río de Janeiro", "La ciudad universitaria de Caracas", "La reconstrucción de Stalingrado" y "Las reformas urbanas de Edimburgo", que muestran una lectura de la Revista Proa en su conjunto con mayor
$7 \quad$ La revista Proa fue una de las varias expresiones que adoptó un grupo de jóvenes arquitectos con enormes pretensiones de cambiar el mundo. Repartida en las páginas de los primeros números y en el libro "Arquitectura en Colombia" que la editorial publicara en 195 I con una selección de las principales obras aparecidas en la Revista entre 1946 y 1951 , se resume toda la ideología del movimiento moderno, potenciada por el énfasis, la confianza y el entusiasmo con que fue vivida a finales de los años cuarenta y comienzos de los cincuenta. ARANGO, Silvia. Historia de la Arquitectura en Colombia, Ed. UNAL. Bogotá, 1989., pp.21। - 212. (...) El debate tuvo como vocero importante a la revista Proa, en la cual se dio la batalla por los principios modernos con toda la vehemencia, la fe $y$ la radicalidad que caracterizó aquellos años. Es correcto afirmar que Proa, la Universidad Nacional y el Ministerio (MOP) conformaron el trípode del surgimiento de la nueva arquitectura en nuestro país. NIÑO, Carlos. Arquitectura y Estado, Ed. UNAL. Bogotá, 1989., p. 241.

Proa fue iniciada en agosto de 1946 representó el cauce editorial del modernismo arquitectónico y su punto de referencia nacional; por lo tanto, es una fuente preciosa para el estudio histórico de la adopción de esa doctrina. En NIÑO, Carlos., Op. Cit., nota 66.

8 Arquitecto egresado de I' Université de París y del Institut d' Urbanisme de la misma escuela (1931); lideró la reorganización de la Sociedad Colombiana de Arquitectos SCA, siendo su primer presidente (1936), y fue el primer Director de la Escuela de Arquitectura de la Universidad Nacional de Colombia UNAL en 1938. Fundó en 1946 junto a Jorge Arango la Revista PROA, fue su director hasta 1976

9 Revista PROA I, Agosto de 1946. 10 Revistas PROA I, 2, 3, de 1946. 
II Revista PROA 2, Septiembre de 1946.

12 Revista PROA 8, Agosto de 1947.

13 En el mes de octubre de 1947 se reunirá en Lima el Sexto Congreso Panamericano de Arquitectos (...) PROA en ánimo de prestar su colaboración en tal certamen sugiere que la Delegación Colombiana estudie y proponga la fundación de un Instituto Panamericano de Planificación con sede en una de las Capitales de América y cuya financiación, reglamentación y fines pueden ser prolijamente estudiados. Editorial Revista PROA 3 Bogotá 1947. (...) Como primer paso hacia ese fin es necesaria la fundación de la filial de la ASCORAL (Asamblée de Constructeurs pour une renovation architecturale). Dicha filial colombiana dirigida por Le Corbusier desde París reportará a nuestro país, nuestras ciudades y a los colombianos en general, beneficios incalculables, porque podrán así vivir de acuerdo con su condición humana y en la forma lógica a que tienen derecho. ARBELÁEZ, Carlos. En "Le Corbusier Polemista" Revista PROA 8, Bogotá 1947.

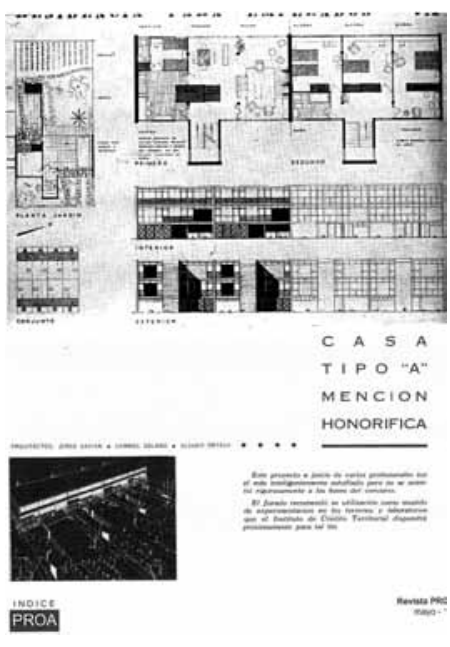

Figura 7. Casa Tipo A intensidad, que apoyan de alguna manera la idea del carácter ilustrado, al mezclar y enlazar ciertas reformas políticas, sociales y económicas que se gestaron y se consolidaron (la Ley de propiedad horizontal y la contratación del Plan a Le Corbusier), del cual se reconoce una visión moderna. Adicionalmente los artículos que se publican sobre Le Corbusier, apuntan no sólo al conocimiento del maestro, sino a la reflexión de sus propuestas, como lo plantea José de Recasens en "El otro Le Corbusier" ", que desarrolla el problema del "estilo" mediante el análisis de su obra pictórica; o el artículo de Carlos Arbeláez, "Le Corbusier Polemista"12 donde se registra el seguimiento continuo y estudio de todas las conferencias, manifiestos y publicaciones realizadas por Le Corbusier desde la publicación del " $L$ 'espirt Nouveau" (1919), hasta "Quand les Cathédrales étaient blanches" (1937). Es así como la Revista PROA se convierte en un actor más; por una parte, de manera directa ilustra sobre los acontecimientos acaecidos como fuente primaria sin distorsiones o manipulaciones, y por otra parte, intenta abrir un Panorama Internacional de ilustración y discusión ${ }^{13}$.

\section{LAS PROPUESTAS ARQUITECTÓNICAS DEL CONCURSO Y SUS PROYECTOS DE VIVIENDA}

El impacto generado por el "concurso de vivienda económica para empleados” a la arquitectura Colombiana está en que, a partir de este, se desplegaron en Colombia dos líneas de acción identificables que las podemos rastrear en los proyectos de vivienda desarrollados por despachos de arquitectos e ingenieros y empresas constructoras que se dedicaran a su proyectación y construcción. La primera de estas líneas la desarrollan empresas (tanto de carácter privado como de carácter oficial), que en su afán de "racionalización", sujetos al aumento de la eficiencia económica o administrativa, se convierten en empresas pioneras en la utilización, experimentación, e importación de tecnología, con el fin de bajar costos al aumentar la producción y reducir el déficit de vivienda, en éstas, participaron algunos de los arquitectos premiados en el concurso (y muchos más) como por ejemplo: la firma “CUÉLLAR, SERRANO, GÓMEZ \& CIA. LTDA.”, formada por el asocio en I 933 de Gabriel Serrano, el Arquitecto Camilo Cuéllar y el Ingeniero José Gómez Pinzón, (todos egresados de la UNAL) a quienes posteriormente, en los años 40, se les unirían el Arquitecto Gabriel Largacha (UNAL) y el Ingeniero Doménico Parma (Turín-Italia).

Fueron sus propuestas las que obtuvieron el segundo premio en la casa tipo A y el tercer premio en la casa tipo B; se destaca en sus propuestas el punto fijo (escalera) como eje de organización espacial, y su continuidad entre el salón y el comedor que acentúa a su costado o en el intermedio el espacio para la biblioteca; en la casa tipo A, separa las unidades de vivienda mediante la zona de servicios (garaje y cuarto de servicio) como espacio libre (que desplaza hacia la fachada); aísla lateralmente el par de casas apareadas, al establecer una pauta a los conjuntos urbanos continuos; contrario al hecho que su propuesta en la casa tipo $B$, establece una continuidad en el conjunto urbano y su desplazamiento de la zona de servicios (cocina y alcoba del servicio) es hacia la parte posterior, desarrollándola de manera lineal al aislar la cocina mediante un patio intermedio con el cuarto de servicio, y reducir el patio posterior en uno de sus costados. Lo que más llama la atención es la modulación estructural realizada para sus propuestas la primera inicia con una modulación $4 \times 3.5 \times 4 \mathrm{~m}$ y muros de carga en el sentido $Y$; la segunda conjuga el sentido de los muros de carga en los sentidos $\mathrm{X}-\mathrm{Y}$, de manera que adquiere una mayor distancia entre ejes con modulación $8 \times 3.5 \mathrm{~m}$. 


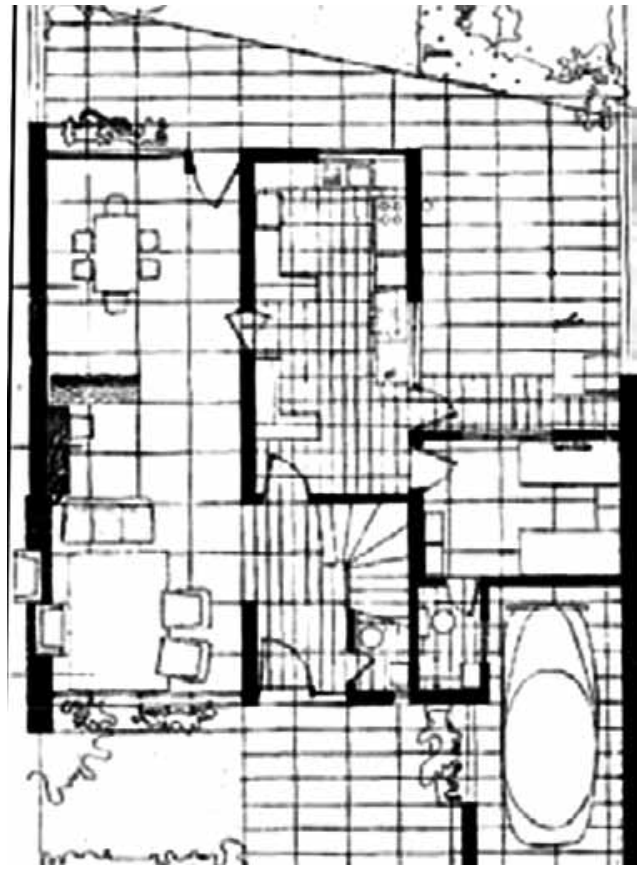

Figura 8. 2do Puesto - Casa Tipo A.

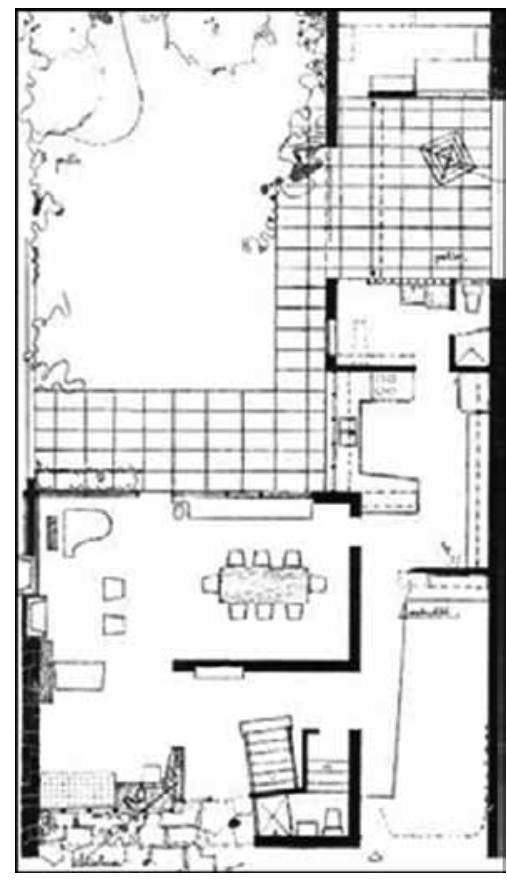

Figura 9. 3er puesto, Casa Tipo B.
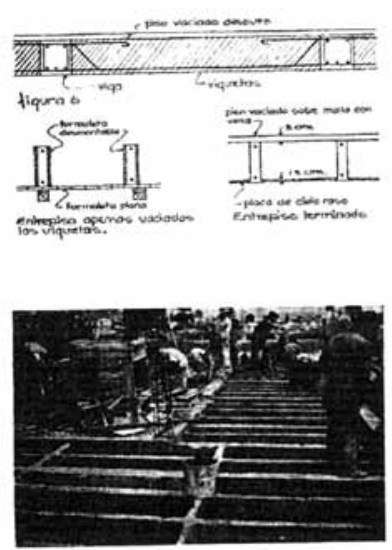

foro 7

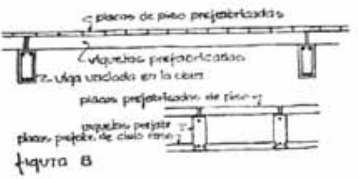

Figura 10. Casas 1, 2, 3 Reticular C
A esta firma de Arquitectos e Ingenieros, posteriormente la Revista PROA le dedica el editorial y su publicación, al desarrollo del Sistema de Construcción Reticular Celulado (Fig. Nos. 8-9), donde explican que "se trata de un novedoso y revolucionario procedimiento de cálculo con su respectiva aplicación práctica en el diseño y empleo de artificios constructivos, que contribuyen en su conjunto a una mejor solución de los entrepisos de concreto" "14; y que adicionalmente, presentan la evolución de los sistemas constructivos de entrepisos hasta el momento desarrollados, respecto al nuevo, con el fin, de mostrar las ventajas de economía en los materiales, en la mano de obra, rapidez en la ejecución, racionalización en la utilización de elementos prefabricados, y su aplicación funcional y de libertad arquitectónica; todo el sistema patentado por sus promotores y confirmado por la Revista. Luego de tres años en la misma revista, se publica la construcción de $14 \mid$ casas económicas para empleados del Banco Central Hipotecario $\mathrm{BCH}$, desarrolladas por la misma firma, donde resaltan especialmente el sistema constructivo utilizado "una estructura en concreto armado del tipo reticular celulado ${ }^{15}$ "; de estas casas se proyectaron tres tipos: el tipo I ( 58 casas, Fig. 10) y el tipo 2 ( 43 casas, Fig. I I) que se distribuyó en tres pisos, en el primero la zona de servicios (alcoba de servicio, garaje y jardín), en el segundo la zona social (cocina, salón y comedor) y en el tercero la zona privada ( 3 alcobas y baño); en el tipo 3 (40 casas Fig. 12) se anuló el garaje, agrupando la zona de servicios y social en la primera planta, y la zona privada en el segundo piso. La reflexión al observar este proyecto es el cambio estructural de muros de carga al sistema porticado, donde se reduce la modulación a una distancia de $2.5 \times 3.5 \mathrm{~m}$ (inverso a lo propuesto en el concurso, el giro del sentido del muro de carga da mayor distancia entre ejes y libertad espacial); bajo esta modulación los cambios en los tres tipos de casas es mínimo, su organización espacial conserva fija la escalera y la planta superior (z. privada) se mantiene igual, lo que constituye una demostración de la estandarización de las dimensiones, con el fin de industrializar (taylorizar) el sistema constructivo aludiendo a una garantía de solidez y estabilidad de la obra. (Fig. I3)
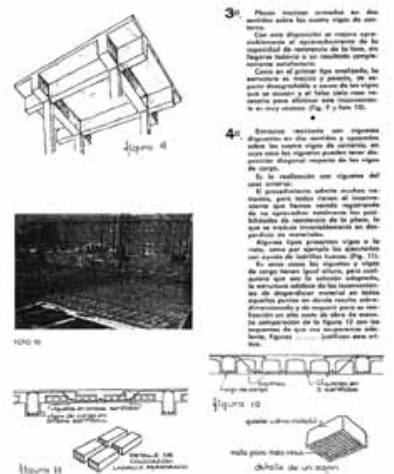

PROA

Figura 11. Casas 1, 2, 3 Reticular C

I3 En editorial "Un revolucionario sistema de construcción: manera de solucionar el problema de los entrepisos en concreto" y "Síntesis del desarrollo en Colombia de las principales estructuras en concreto armado". Revista PROA 33, Marzo de 1950

14 En editorial "Un revolucionario sistema de construcción: manera de solucionar el problema de los entrepisos en concreto" y "Síntesis del desarrollo en Colombia de las principales estructuras en concreto armado". Revista PROA 33, Marzo de 1950

15 En "Conjunto de Casas Económicas", Arquitectos Cuellar, Serrano, Gómez \& Cía. Revista PROA 70, Abril 1953. 


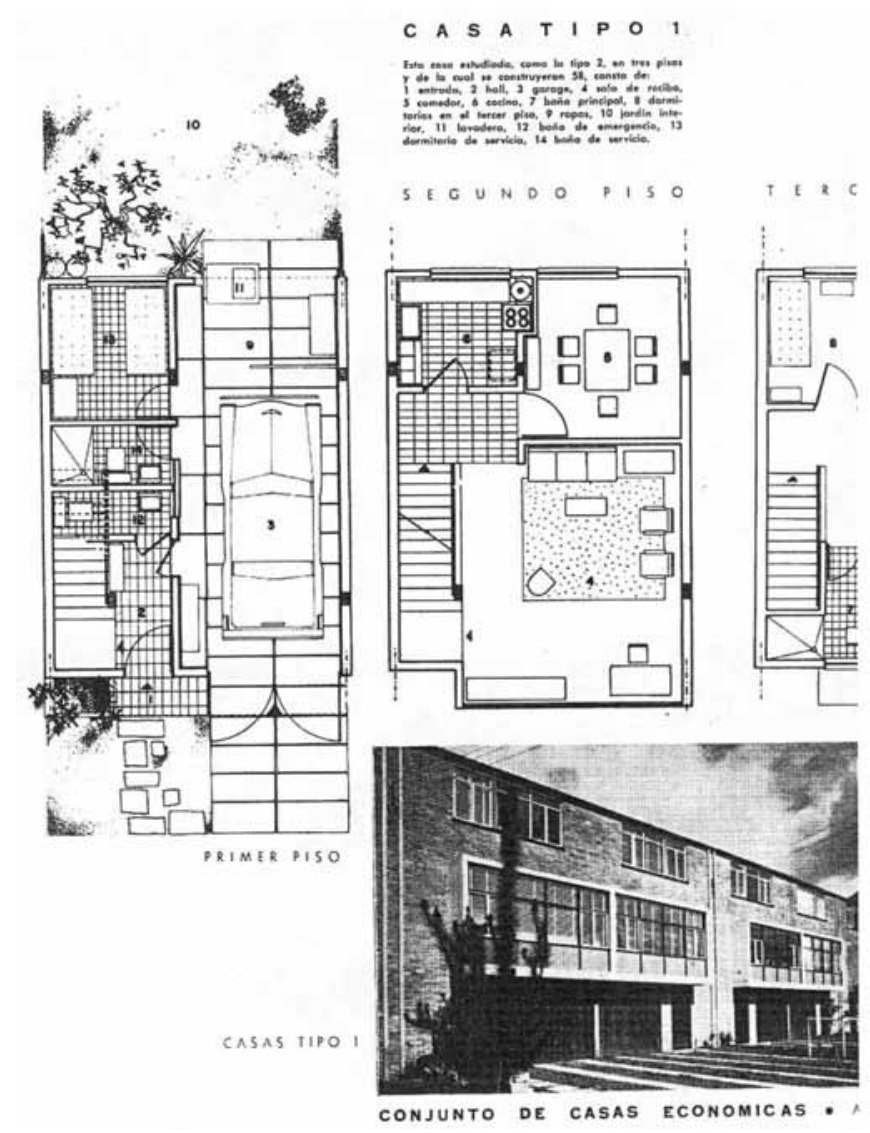

Figura 12

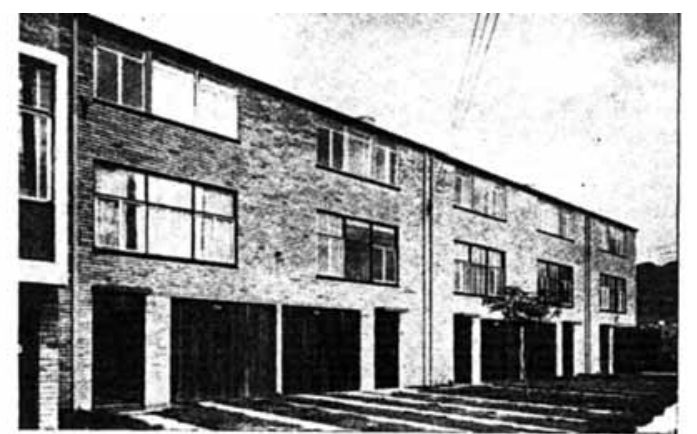

$\begin{array}{llllllll}C & \text { A A } & T & \text { I } & \text { P } & 0 & 2\end{array}$
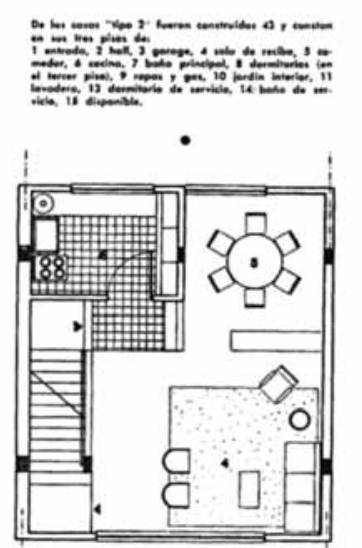

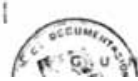

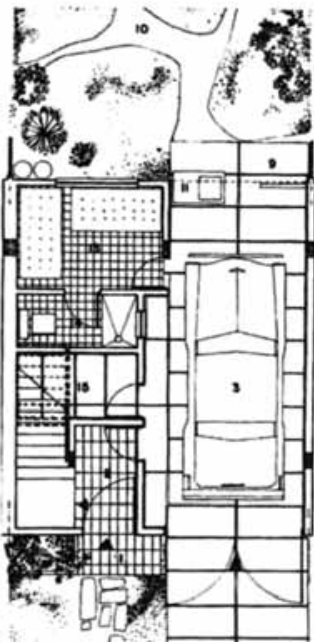

Figura 13

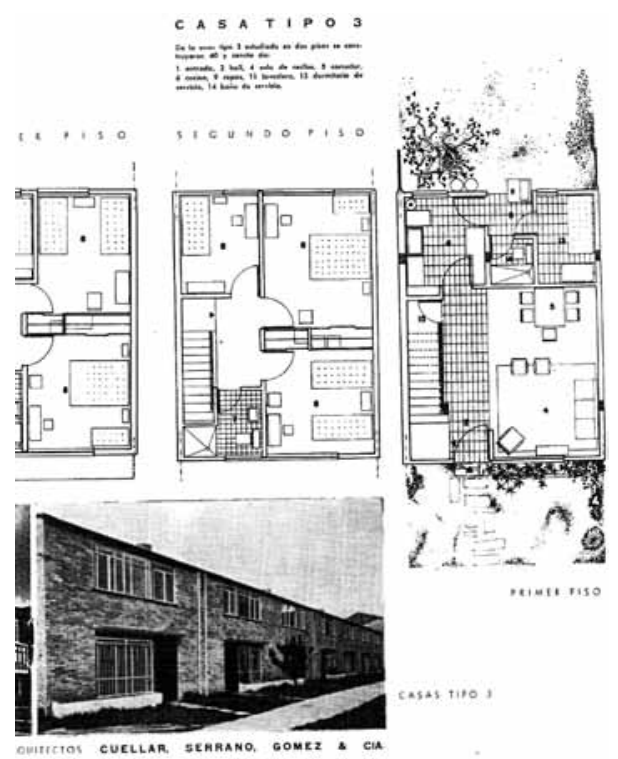

Figura 14
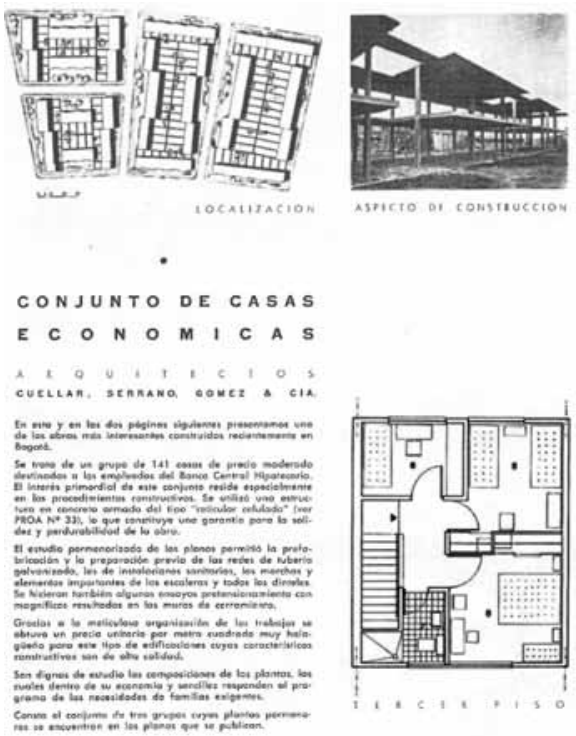

Figura 15

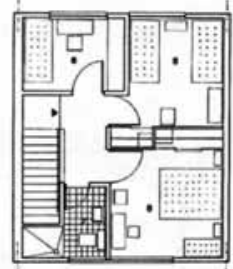

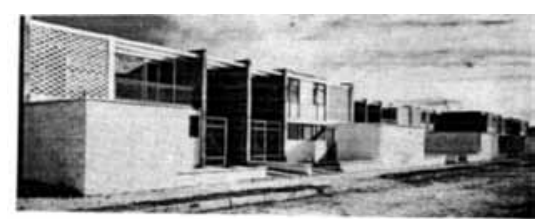
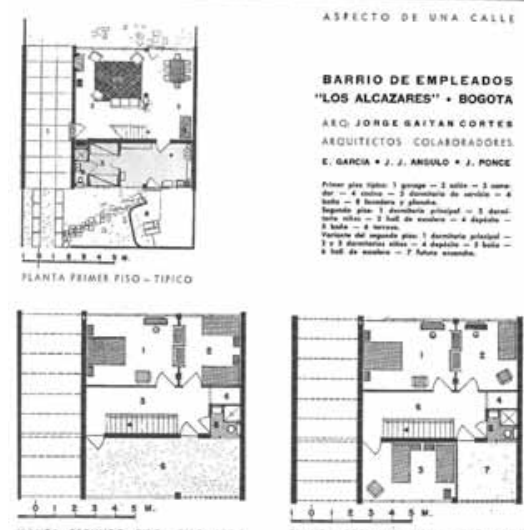

Figura 16 
El otro grupo de arquitectos que desarrollaron esta línea de "racionalización" y experimentación tecnológica, fueron los arquitectos Jorge Gaitán, Gabriel Solano y Álvaro Ortega, quienes obtuvieron una Mención en la casa tipo A (Figura 16). Su propuesta aplica algunos de los "principios para la nueva arquitectura" de Le Corbusier: el primero que emplean es su sistema constructivo sobre pilotes, el cual lo margina de los primeros puestos del concurso (por estar este sistema fuera de las bases del concurso); el segundo libera la planta, con la cual consiguen mayor libertad espacial al sacar la escalera hacia la fachada; adicionalmente los grandes ventanales en ambas fachadas corridas, y a pesar de las diferencias programáticas, termina por asumir rasgos comunes a las viviendas de Weissenhof de Stuttgart ( 1927) en su continuidad lineal, y a la Loucheur (1929) en su movilidad espacial, diseñadas por Le Corbusier.

El ejemplo, en esta oportunidad desde la empresa estatal, es el diseño y la construcción del barrio de "Los Alcázares" (Figura 17), llevada a cabo por el Ingeniero Posada Cuéllar gerente del ICT, y la colaboración de un grupo de arquitectos liderados por Jorge Gaitán Cortés, quienes desarrollaron 52 casas de un total de 137 (las restantes fueron adjudicadas por licitación a otras tres firmas de arquitectos con proyectos personales); lo interesante de ésta, no fue sólo la distribución en planta (servicios hacia delante-el antejardín- y el área social salón-comedor en un solo espacio hacia atrás, omitido el vestíbulo) de las cuales, la primera planta es estándar y la segunda con cuatro variaciones en sus dependencias y capacidades; sino también, el aporte de nuevos materiales estandarizados que contribuían al mejoramiento de la construcción y a la economía de la misma. A este proyecto, una vez más, la Revista Proa le dedica un número especial, en la cual se presentaba un balance a la fecha del ICT, y una descripción detallada del proyecto en la parte Urbana, Arquitectónica y especialmente, en su Técnica Constructiva de la siguiente manera: "El Instituto de Crédito Territorial (...), puso al servicio de las casas que construyó un moderno y bien dotado laboratorio de materiales. En sus talleres se produjeron, por procedimientos de prefabricación, vigas en concreto para reemplazar los entresuelos en madera (...) marcos de concreto en dimensiones moduladas para las fachadas; ladrillos de especificaciones físicas muy novedosas y a precio bajo y una infinidad de muy variados elementos constructivos que en forma de bloques contribuirán al mejoramiento de los muros en lo que a peso, rapidez en el trabajo, economía y exigencias de aislamiento se refiere"16.

Luego de la culminación de Los Alcázares, el equipo del ICT y de Gaitán Cortés emprenden el desarrollo de "tres unidades vecinales" de casas obreras, para distintas ciudades colombianas (374 casa en Cúcuta, 346 casa en Tuluá, Valle y I.030 en Muzú, Bogotá) que válida la anterior experiencia, con un mínimo de variaciones con el fin de sistematizar y estandarizar su sistema constructivo; las casas de Muzú, se construyeron en filas de ocho casas, prefabricando muros y lozas en concreto pre-vaciados y procesados en el suelo, aplicándole los procedimientos del concreto al vacío, para que luego de 24 horas de fundidos fueran levantados por un sistema de ventosas y colocados a manera de "armo todo", sellando las uniones en concreto y obteniendo un conjunto estructural monolítico. Este sistema constructivo fue implementado en colaboración de tres empresas: el equipo del ICT, la empresa de Arquitectos e Ingenieros "ORTEGA SOLANO Y GONZÁLEZ ZULETA CÍA. \& LTDA (Arquitectos Gabriel Solano, Álvaro Ortega, e Ingeniero Guillermo González Zuleta), y VACUUM CONCRETE Co. Posteriormente en el Barrio Quiroga de Bogotá (1953) se construyeron un total de 1.970 casas, donde se mejoran los sistemas constructivos y se emplean: el entrepiso reticular celulado, y las bóvedas aligeradas construidas en situ (producción en serie), para posteriormente ser levantadas y colocadas como parte del techo, cubriendo una superficie de $22 \mathrm{~m}^{2}$.
I6 En "El nuevo Barrio de los Alcázares: concentración de casas para empleados ejecutadas por el Instituto de Crédito Territorial". Revista PROA 20, Octubre de 1949. 
La otra línea promovida por acción del concurso está liderada por un grupo más joven de arquitectos, que abordaron un proceso de "racionalización" más cercano a lo social y lo cultural, debido a estar próximos a recibirse como arquitectos Fernando Martínez y Hernán Vieco, quienes desde la academia iniciaron su reflexión sobre la vivienda económica popular y la continuaron mediante su ejercicio profesional, de manera que logran prematuramente hacer parte del grupo de diseñadores que participan en la reconstrucción de Tumaco con Wiener y Sert; esta línea de acción se apartó de la fría modulación y estandarización, buscó un interés particular por el lugar (contexto), que inicia al indagar por las particularidades físicas del clima y la topografía, y finalizan por las condiciones contextuales culturales expresivas del paisaje y de sus materiales constructivos.

Su propuesta de vivienda avanzó gradualmente desde sus planteamientos en el concurso (Figura 18), en la que desplazaba los servicios hacia la fachada, dejando hacia la parte posterior el área de salón social y comedor en comunicación directa al jardín interior; estrategia que mantuvo en este caso en compañía del arquitecto Jaime Ponce en los siguientes proyectos, aprovechándose de la profundidad de los solares; adicionalmente con el manejo de la topografía en la organización de los espacios, del ordenamiento y la sencillez de las fachadas, adelantó un conjunto de casas económicas en el barrio "el Retiro" (Figura 19) construidas por la firma y publicadas en dos oportunidades por la revista PROA ${ }^{17}$. El ordenamiento en las fachadas propuesto por este grupo de arquitectos avanzó al romper la ortogonalidad de sus volúmenes, valiéndose del manejo topológico y el uso de materiales y texturas, lo que generó una nueva plástica ligada a la expresividad del paisaje.

Cabe destacar dos consideraciones propias de sus propuestas; la primera es que en todas mantuvo siempre un desarrollo particular de avance, de dichas intervenciones en viviendas apareadas, sin dar importancia alguna a ningún distingo social, pues todas fueron trabajadas con el fin de dignificar la vivienda popular; por otra parte, al tema de la construcción industrializada se resistió de manera radical, ya que sus viviendas mantenían una escala de trabajo particular, sus áreas nunca fueron minimizadas (con fines de rentabilidad económica), y sus propuestas en dimensiones respecto al despacho en las que realizaba consultoría y construcción contaron con materiales propios del lugar y adecuados a su economía, como la casa diseñada para su familia. (Figura 20)

Figura 18

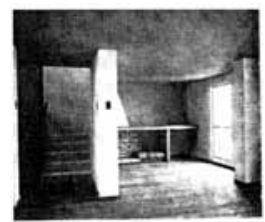
CUATRO CASAS EN BOGOTA

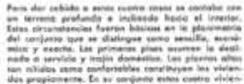

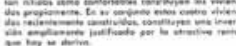
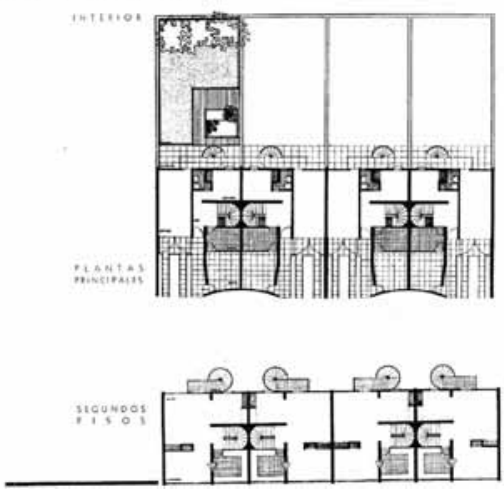

Figura 17

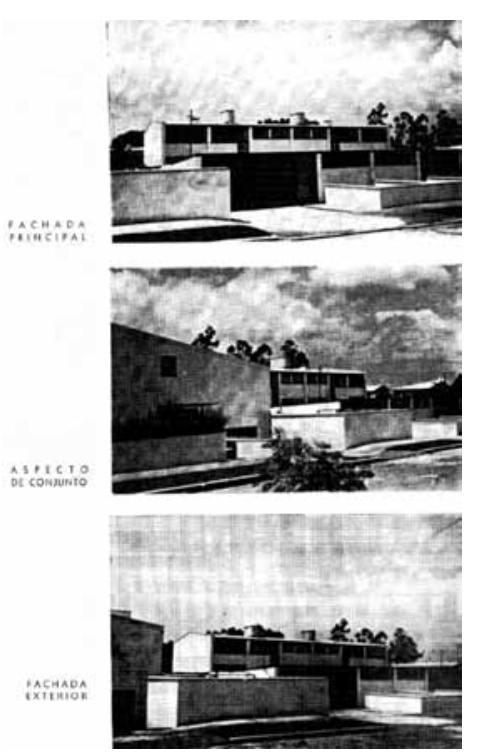


La otra firma de arquitectos que participaron en el concurso y actuaron dentro de esta misma línea de acción fueron los arquitectos Rafael y Jesús María Obregón \& Pablo Valenzuela, quienes fueron acreedores del primer puesto del concurso en la vivienda tipo A; su propuesta de excelente calidad espacial, integra al amplio salón comedor un espacio para la lectura, sin embargo, le crea su privacidad al aislarlo del hall de entrada, mediante la disposición de la chimenea; así mismo, desplaza la zona de servicios al costado de forma lineal y hacia la fachada; lo que genera una gran zona libre de antejardín para cultivo o recreo y un jardín interior como área de reposo. Todas estas calidades de diseño fueron plasmadas por Rafael Obregón, en su propia casa (Figura 2 I -22) alabada y publicada por la Revista $\mathrm{PROA}^{18}$; gesto que gran parte de los arquitectos de esta época experimentaron al diseñar y construir sus propias casas, algunos con el uso de novedosos sistemas constructivos, otros bajo una búsqueda estética, dieron origen a ejemplos emblemáticos de la arquitectura moderna colombiana. Es el caso de la Casa del Arquitecto Francisco Pizano (195I) y Guillermo Bermúdez (1953) en las que utilizaron las bóvedas aligeradas sobre plantas cuadradas o rectangulares; la casa de Gabriel Largacha (1949), Gabriel Serrano (1950) y de Jaime Nieto Cano (1950), sus diseños parten de una estricta modulación con el fin de utilizar elementos prefabricados y bajar los costes de construcción.

La casa de Rafael Obregón (1949), busca continuar las calidades espaciales iniciadas en el concurso, mediante el uso de materiales y las dobles alturas en los espacios sociales, adicionalmente, distribuir en los espacios libres de antejardines y jardines interiores actividades específicas destinándolas, por ejemplo, a huertos, Jardín, patio de servicio, o terrazas de descanso; experiencia que se traduce a varios proyectos de vivienda popular, entre ellos el que desarrollaron para los empleados en Barranquilla promovido por el BCH (dentro de su política de encargar los proyectos regionales a profesionales ligados a estas zonas, de manera que se minimizasen errores de diseño y construcción); esta propuesta de un total de $8 \mathrm{I} \operatorname{casas}^{19}$, contó con áreas generosas en las cuales se proyectaron dos tipos de vivienda
18 En Revista PROA 29, de Noviembre de 1949.

19 En Revista PROA 86, de Febrero de 1955.

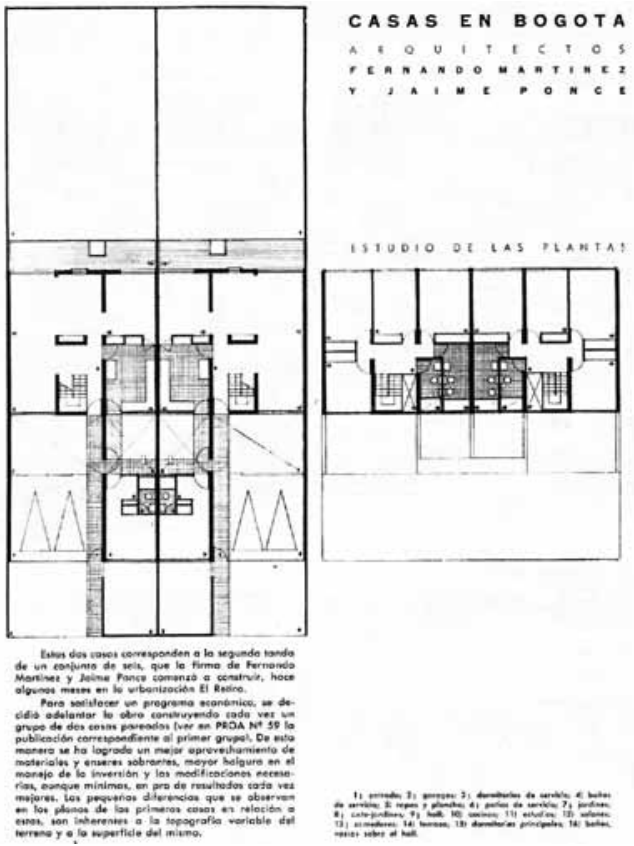

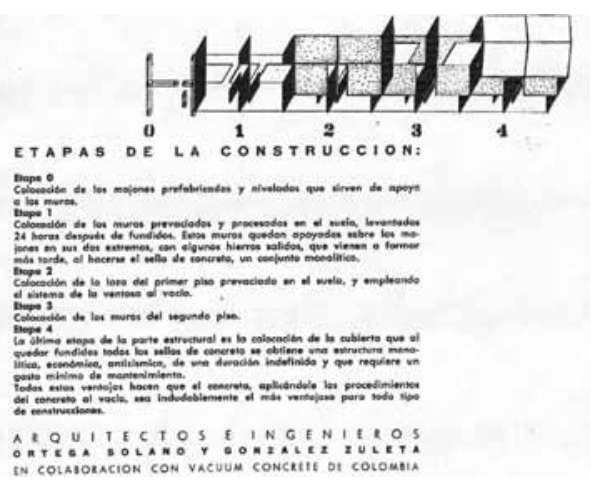

Figura 20 
de dos pisos y otros dos de un piso, todos los tipos plantearon tres cuartos, aislamientos laterales, y patios interiores de manera que se obtuviera una muy buena iluminación y ventilación; en la casa tipo A (Figura 23), se destaca una mayor área construida, cuenta con un hall de entrada, y adicionalmente un área social conjunta de salón - comedor a doble altura, con relación directa al jardín interior; en la casa tipo B (Figura 24 -25), se compacta el Hall y el salón comedor, al desplazar los servicios al costado y mantener la relación directa al patio interior.

Finalmente, es necesario destacar que el tema de la vivienda obrera fue abordado en todos los ámbitos, desde lo público como: el Ministerio de Obras Públicas (MOP), el Instituto de Crédito Territorial (ICT), el Banco Central Hipotecario (BCH); desde lo privado: el Instituto de Acción Popular, (que más adelante se llamaría "Caja de Vivienda Popular", con capital mixto) las empresas consultoras y constructoras de Arquitectos e Ingenieros, y la Revista PROA; desde los gremios: de Arquitectos SCA, de Ingenieros SCl, y de Constructores; desde lo Académico: La Universidad Nacional de Colombia (1938), la Pontificia Universidad Bolivariana (1942), la Universidad del Valle (1947), la Universidad de los Andes (1949), y la Universidad Javeriana (1950); adicionalmente, que muchas de estas instituciones fueron lideradas y promovidas por la mayoría de los participantes del concurso, es decir, todos los actores y gestores de estas instituciones, generaron un ambiente de discusión y experimentación digno de ser revisado con detenimiento, máxime cuando se está actuando sobre una población, que se entiende ser la base de una sociedad moderna.

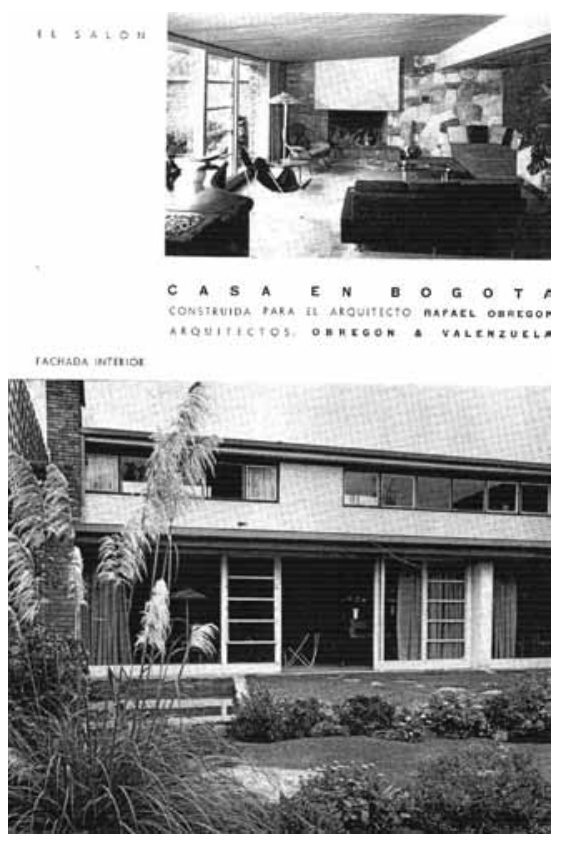

Figura 21

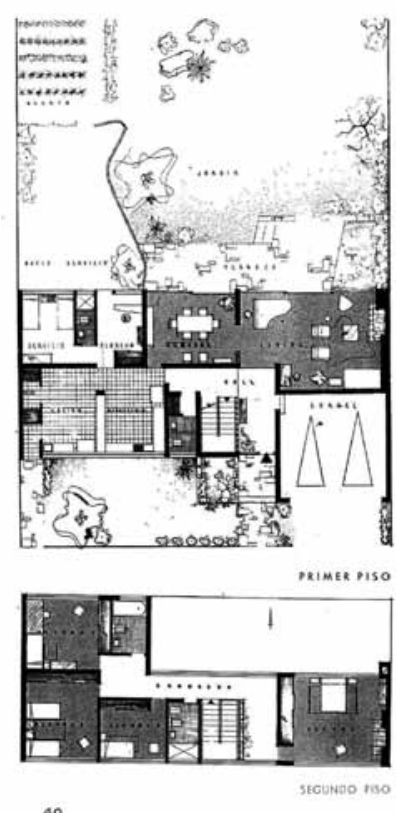

Figura 22 

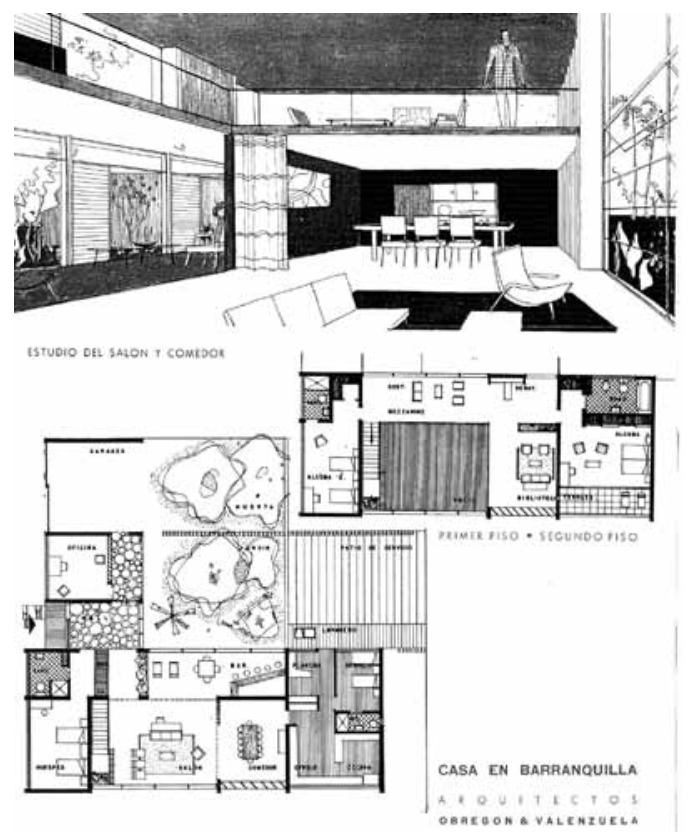

46 ctartin 6 mingresto

Figura 23
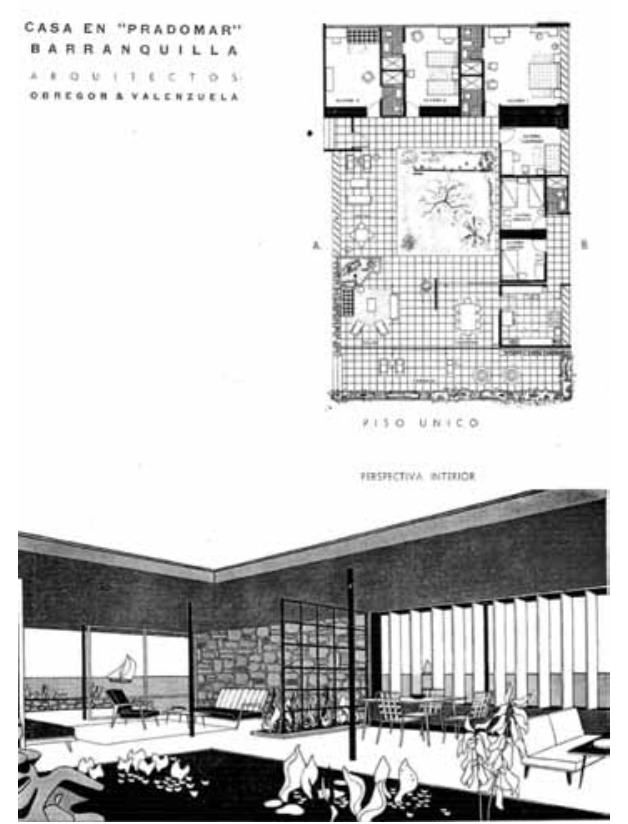

Figura 24

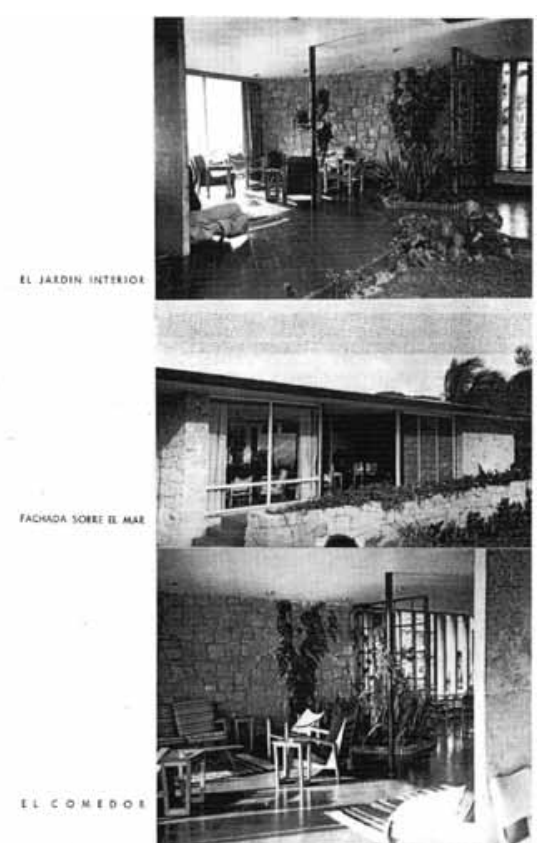

Figura 25 


\section{BIBLIOGRAFÍA}

ARANGO, Silvia. Historia de la Arquitectura en Colombia, Editorial UNAL, Bogotá 1989.

ARANGO, Jorge \& MARTÍNEZ, Carlos. Arquitectura en Colombia, Editorial Proa, Bogotá 195I.

CABALLERO, Jorge Enrique. Barranquilla y la Modernidad: un ejercicio histórico, UNAL, Bogotá, 1999.

HABERMAS, Jürgen, Conocimiento e Interés. Taurus Ed. Madrid, 1982.

El Discurso Filosófico de la Modernidad. Taurus Ed. Madrid, 1989.

LE CORBUSIER, Hacia una arquitectura, Ed. Poseidón, Barcelona, 1998.

La Casa del hombre, Ed. Poseidón, Barcelona, 1999.

Cuando las catedrales eran blancas, Ed. Poseidón, Barcelona, 1972.

Precisiones, Respecto a un Estado Actual de la Arquitectura y el Urbanismo.

Ed. Poseidón, Barcelona, 1998.

MONDRAGÓN, Hugo. El Proyecto Moderno en Bogotá: Arquitectura en Colombia, 1946

- 195I, Lectura crítica de la revista Proa. Revista Textos No. I2 UNAL, Bogotá 2005.

NIÑO, Carlos. Arquitectura y Estado, Editorial UNAL, Bogotá I99I.

PROA. Revistas Números I - 2-3-7-8-20-28-29-33-44-59-69-70-86

- 125, Bogotá 1947 - 1953.

RODRÍGUEZ, Gabriel. El Proyecto Moderno en Bogotá, La Exposición Nacional del IV Centenario de Bogotá. Revista Textos No. 12 UNAL, Bogotá 2005.

ROMERO, José Luis. Latinoamérica: las ciudades y las ideas, Siglo XXI editores, Argentina, 2001 .

ROWE, Colin. Manierismo y arquitectura moderna y otros ensayos, Editorial Gustavo Gili, Barcelona, 1999.

SALAZAR, José y Otros. Patrimonio urbano en Colombia, Colcultura, Bogotá, 1996.

SALDARRIAGA, Alberto. "Arquitectura y cultura en Colombia". UNAL Ed. Bogotá, 1986. 
SAMPER, Eduardo. Arquitectura moderna en Colombia, Ediciones Diego Samper, Bogotá 2000.

TORRES, Jorge. Le Corbusier: visiones de la técnica en cinco tiempos, Ediciones Fundación Caja de Arquitectos, Barcelona 2004.

VIVIESCAS, Fernando \& GIRALDO, Fabio. (Compiladores) "Foro Nacional por Colombia”, Ed. Bogotá, 1991. Y

Pensar la Ciudad”. CENAC- FEDEVIVIENDA \& TM Ed. Bogotá, 1996.

ZEVI, Bruno. Saber Ver la Arquitectura, Ed. Poseidón, Barcelona, 1998. 